\title{
The effects of hillslope forage crop grazing in winter on soil erosion
}

\author{
V.M. PENNY ${ }^{1}$, P.C. ALMOND ${ }^{1}$, S. LAURENSON ${ }^{2}$ and A. KLIK ${ }^{3}$ \\ ${ }^{1}$ Soil and Physical Sciences Department, PO Box 85084, Lincoln University, Lincoln 7647, New Zealand \\ ${ }^{2}$ AgResearch, Lincoln Research Centre, Private Bag 4749, Christchurch 8140, New Zealand \\ ${ }^{3}$ University of Natural Resources and Life Sciences, Muthgasse 18, A-1190, Vienna, Austria
}

Veronica.Penny@lincolnuni.ac.nz

\begin{abstract}
Farming intensification has led to a greater use of forage crops to feed cows over winter. This farming practice is now commonly taking place on rolling to steep land in areas where stock are wintered off-farm, such as Southland and South Otago. While the impacts of forage crop grazing on soil physical properties such as compaction, and overland flow of nutrients, sediment and pathogens have been studied, there is a lack of understanding of how this practice influences soil transport. This study used a novel technique to quantify the rate soil is pushed downslope by the hooves of cows while grazing kale, and found a linear relationship between soil transport and slope for slope gradients of less than 0.25 . The steep slope of the linear relationship, which defines the soil transport coefficient, indicates rapid downslope soil movement relative to slope gradient. As a consequence, soil erosion on convex sites occurs at rates that likely exceed soil production rates. The formation of stock tracks on slopes greater than 0.25 caused greater uncertainty in soil transport rates, and more research is required to determine the effect of track formation on soil movement.
\end{abstract}

Keywords: winter cropping, brassica, forage crops, erosion, soil creep

\section{Key messages}

- Cattle treading during winter forage grazing on hillslopes caused rapid downslope movement of soil

- Soil transport caused redistribution of soil on hillslopes: erosion on convex sites and accumulation on concave sites

- Over half of the erosion rates on convex areas exceeded soil production rates, and will reduce topsoil thickness.

\section{Introduction}

Land-use change has lead to an intensification of farming in New Zealand over the last two decades, with dairy cow numbers increasing from 3.84 million in 1994 to 6.70 million in 2014. In the Southland region, this intensification of land use has been even more substantial, with an increase in dairy cow numbers from 114000 in 1994 to 700000 in $2014(>600 \%$ increase) (Statistics New Zealand 2014). Together with a higher proportion of animals being wintered under dairying compared to dry-stock farming (Morris 2013), intensification has resulted in more demand for winter feed for stock. High-energy forage crops such as brassicas are break-fed to cows over winter to fill the feed deficit caused by slow pasture growth (de Ruiter 2009; McDowell \& Houlbrooke 2009). Break-feeding of brassica crops leaves soil with no vegetation cover and little in the way of root systems to protect against erosion. Coupled with winter grazing of crops when soil is wet and has less strength, this system leaves soils vulnerable to structural damage, accelerated movement downslope and erosion (McDowell \& Houlbrooke 2009).

Forage crop grazing with cows causes greater soil structural damage (compaction) relative to sheep, due to their increased weight (Houlbrooke et al. 2011; McDowell \& Houlbrooke 2009). Soil compaction reduces water infiltration, and thus leads to greater overland flow during rainfall events, which has been found to cause surface erosion, particularly in areas where water flow accumulates (McDowell \& Houlbrooke 2009; Orchiston et al. 2013). Orchiston et al. (2013) found grazing of critical source areas where water concentrates resulted in greater erosion than if these areas were avoided when wet, under forage crop grazing in a similar catchment to the current study. While previous work has identified the potential for winter grazing to cause soil structural damage and erosion via overland flow, there have been no published data on the volume of soil that is physically pushed downslope beneath the hooves of cows. This paper reports soil transport and erosion rates via gradual soil movement ('creep') under winter forage crop grazing on rolling land, and identifies areas where the rate of soil loss is unsustainable.

\section{Methodology}

\section{Site description}

The research area was a 6 ha flat to hilly paddock (LUC: 3e12) at c. $40 \mathrm{~m}$ a.s.l. on the Telford Farm Training Institute near Balclutha, South Otago (46 $16^{\circ}$ $45^{\prime \prime} \mathrm{S}, 169^{\circ} 42^{\prime} 22^{\prime \prime}$ E). The soil is a Mottled Fragic Pallic silt loam belonging to the Timaru series. These soils are characterised by a dense subsurface horizon, which can perch water, and have low structural stability 
which makes them prone to pugging and structural degradation (Landcare Research 2015).

The farm has a mean annual temperature of $9.8^{\circ} \mathrm{C}$ and mean annual rainfall of $680 \mathrm{~mm}$. The paddock was grazed between 16th June and 30th July 2015, when mean air temperature and total rainfall were $4.8^{\circ} \mathrm{C}$ and $163 \mathrm{~mm}$, respectively. These figures compare to longterm mean June-July temperature of $5.0^{\circ} \mathrm{C}$ and rainfall of $120 \mathrm{~mm}$ (NIWA 2015).

The paddock was planted in Regal ${ }^{\circledR}$ kale (Brassica oleracea spp. acephala) in early December 2014, after being in kale the previous season, and in perennial ryegrass (Lolium perenne) and white clover (Trifolium repens) pasture before 2013. The 2015 kale crop yielded c. 15 tonnes DM/ha and was grazed by a herd of 123 pregnant non-lactating dairy cows. Crop allocation was c. $6.1 \mathrm{~m}^{2} /$ cow/day with break fences shifted twice daily (progressing in a downslope direction), and grass silage bales supplementing their diet. The use of portable water troughs removed the need for the cows to regularly walk the length of the paddock to get water, thus reducing trampling of the soil. Cows were prevented from accessing the gateway by the use of a back-fence and, although no other back-fences were used, cows were observed to spend the majority of their time eating and resting along the crop-face.

The area used for this research covered 3.4 ha of the paddock, and consisted of a flat crest with a hillslope that descended on the eastern side of the paddock. Along the eastern boundary was a pine plantation bordering an ephemeral stream. Total difference in elevation was $17 \mathrm{~m}$.

\section{Experimental setup}

A digital elevation model (DEM) of $2 \mathrm{~m}$ resolution was generated in May 2015, and was used to determine the positioning of ten study transects within the research area (Figure 3a). The locations of these transects were chosen based on the surface gradient and encompassed a representative sample of all gradients present in the paddock. Surface elevations from which the DEM was derived were captured using a Trimble R6 Real Time Kinematic (RTK) GNSS surveying system and a Trimble TSC3 controller. Individual points were recorded with the RTK rover on a backpack and the system on continuous topography mode to record a point every $3 \mathrm{~m}$. The RTK has a horizontal accuracy of $\pm 8 \mathrm{~mm}$ and a vertical accuracy of $\pm 15 \mathrm{~mm}$ when measuring a static point. However, the movement of a person walking adds an undetermined inaccuracy to the data points when the backpack is utilised. Data obtained from the GPS were processed in ArcGIS version 10.3.

Soil transport over the duration of the experiment was estimated by measuring the movement of 18 mm-diameter hardened steel balls. Two hundred balls

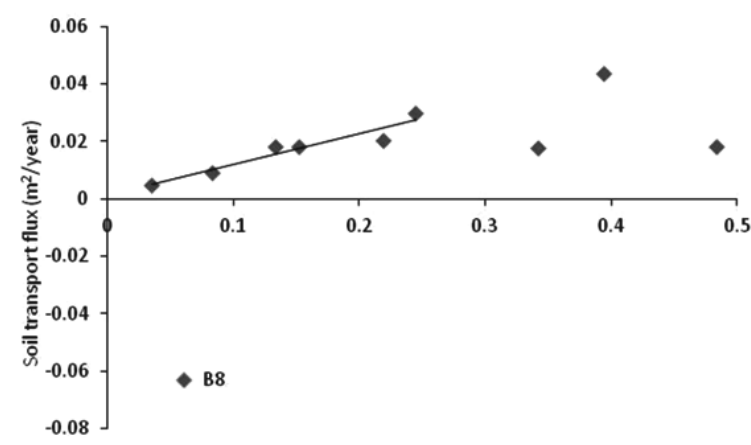

Figure 1 Soil transport flux $\left(q_{s}\right)$ at different slope gradients $(S)$, with a linear regression line for gradients $(S)$ of $<0.25$ (excluding the outlier at transect B8), where the relationship was determined to be $q_{s}=0.107 \mathrm{~S}$ $+0.001\left(R^{2}=0.91, P=0.003\right)$.

were engraved with individual numbers and 20 balls were placed at each of the ten transects. Eight balls were placed at $50 \mathrm{~mm}$ depth below the soil surface, eight balls at $150 \mathrm{~mm}$, and four at $250 \mathrm{~mm}$ depth. The reduced intensity of balls with depth was based on an expectation of reduced transport with depth. The position of each ball was measured at the soil surface, using the RTK GPS and recorded against the ball's individual engraved number. The balls were placed in the soil in late May by augering $4 \mathrm{~cm}$ diameter holes perpendicular to the surface, placing the ball at the specified depth and back-filling the hole. Balls were left in the soil over the winter grazing period and the research area was grazed as detailed above.

The steel balls were recovered in September 2015, after the research area had been grazed and the cows were no longer in the paddock. The balls were relocated using a Garrett AT Pro metal detector and the exact location determined with a Bounty Hunter pin pointer metal detector. The soil above the ball was excavated; when the ball was exposed, its vertical depth below the soil surface was measured. Its spatial location was also measured using the RTK GPS. The metal detector failed to register balls deeper than $160 \mathrm{~mm}$. For these balls, their original position was resurveyed using the RTK GPS, and then overlying soil was removed progressively until they were detected. As there was marginal soil movement below $160 \mathrm{~mm}$, this technique allowed all of the deeper balls to be located.

After the balls had been located, high resolution DEMs of the ten transects were created by measuring topographic points with the RTK GPS at a density of 0.25 to $1 \mathrm{~m}$, depending on the terrain. Higher resolution DEMs enabled us to more accurately determine the effect of gradient on soil transport, and assisted with the identification of cattle tracks on steeper slopes.

\section{Data analysis}

Data processing was done using ArcGIS (version 

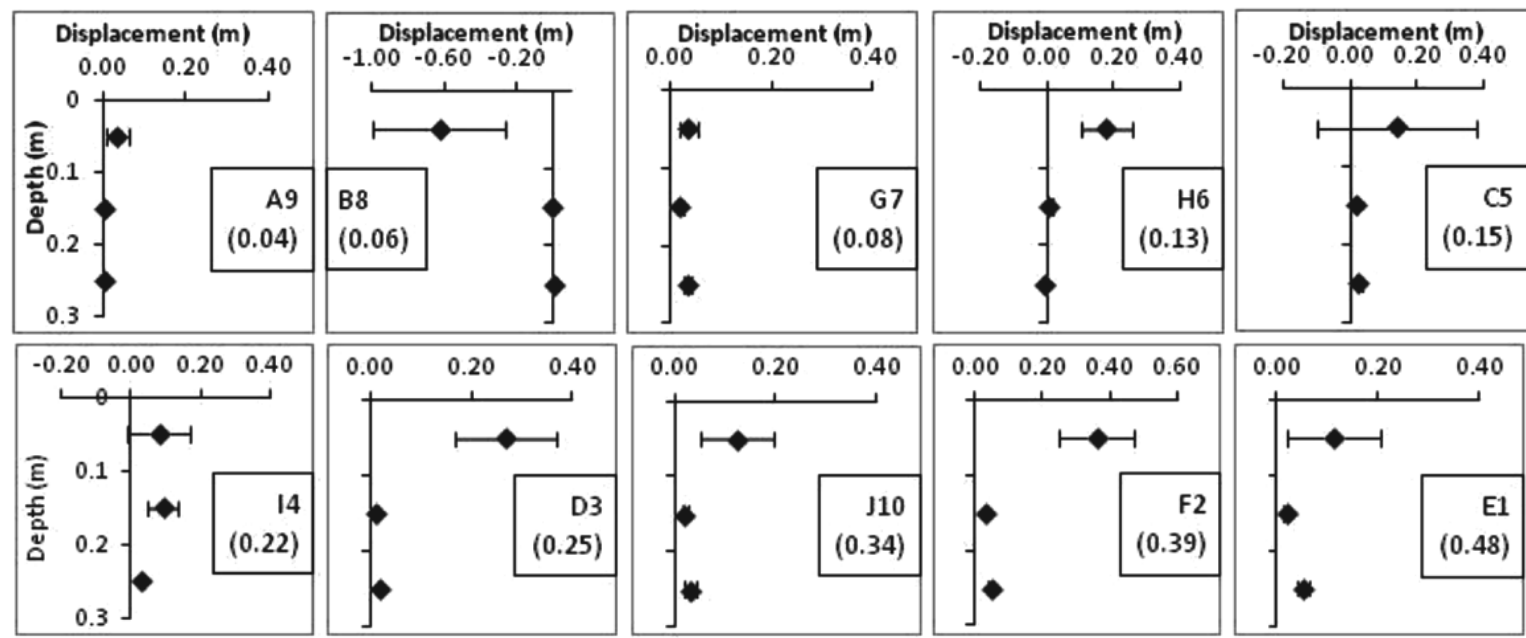

Figure 2 Average downslope displacement $(\mathrm{m})$ of soil at 0-100 mm, 100-200 mm and 200-300 mm depths. Plot number corresponds to transect ID and slope gradient is in parentheses. Error bars are standard error of the mean.

10.3) to create DEMs, visualise data and create maps. Microsoft Office Excel (2007) was used to calculate ball positions and soil transport, and run regression analysis on data outputs. Slope, curvature and aspect maps were generated from the DEM using ArcGIS's Spatial Analyst tools.

Placement of the balls in auger holes drilled perpendicular to the soil surface, in contrast to excavation of relocated balls in a vertical manner, created an apparent uphill displacement of balls that had not moved; balls buried deeper had a greater apparent displacement. This difference in approach was an oversight, and was corrected using a trigonometric calculation, based on soil depth and slope gradient derived from the detailed DEMs, to place original and final positions in the same $\mathrm{x}, \mathrm{y}, \mathrm{z}$ coordinate system.

Pre- and post-grazing positions were converted to displacement vectors using the Theorem of Pythagoras and trigonometry. Displacement vectors were then projected onto the gradient vector (aligned with the slope aspect) to determine downslope displacement. Downslope displacements for each of the three depths were averaged, and then volumetric soil transport was calculated, assuming the motion of balls at $50 \mathrm{~mm}$, $150 \mathrm{~mm}$ and $250 \mathrm{~mm}$ depths represented the depth increments 0-100 mm, 100-200 mm, and 200-300 mm, respectively. Finally, volumetric transport over the three depth increments were summed and converted to an annual soil transport flux, assuming that the grazing event observed was representative of standard winter grazing practice in any given year.

\section{Theoretical background}

Where soil transport on a hillslope is driven by shallow soil disturbance, the volumetric flux of creeping soil is often directly proportional to hillslope gradient as per equation 1:

$$
q_{s}=-K S \quad \text { (equation 1) }
$$

where $q_{s}$ is the volumetric soil flux measured in $\mathrm{m}^{3}$ per $\mathrm{m}$ length of contour per unit time ( $\mathrm{m}^{2} /$ year), $K$ is a transport coefficient $\left(\mathrm{m}^{2} /\right.$ year $)$ derived from the relationship between soil transport flux and slope gradient (Figure 1) and $S$ is hillslope gradient $(\mathrm{m} / \mathrm{m})$. The negative sign ensures a positive flux occurs in a downslope direction. The aim of the experimental work was to ascertain if this relationship holds for soil transport under cattle trampling on sparsely vegetated hillslopes where soils are saturated. If soil transport can be modelled by linear slope-dependent transport then soil transport rate can be predicted simply from slope gradient, and the rate of erosion $(E ; \mathrm{m} /$ year $)$ is given by equation 2 :

$$
E=-K C \quad \text { (equation 2) }
$$

where $C$ is the hillslope curvature (per $\mathrm{m}$ ). Curvature describes the rate at which gradient changes. The negative sign in equation 2 ensures that landscape elements with convex (negative) curvature yield positive erosions rates, whereas elements with concave (positive) curvature result in negative erosion rates (i.e. deposition).

\section{Results:}

The effect of slope gradient on soil transport under cattle treading was greater downslope movement the steeper the slope (Figure 1), with shallow balls moving further than deep balls (Figure 2). Depth integrated soil transport was found to have a significant $(\mathrm{P}=0.003)$ positive linear relationship with gradient for gradients less than $0.25\left(c .14^{\circ}\right)$. The slope of the regression line, which is equivalent to the transport coefficient, $K$, was $0.11 \pm 0.02 \mathrm{~m}^{2} /$ year (Figure 1). Transport on steeper slopes was highly variable and appeared to relate to a 

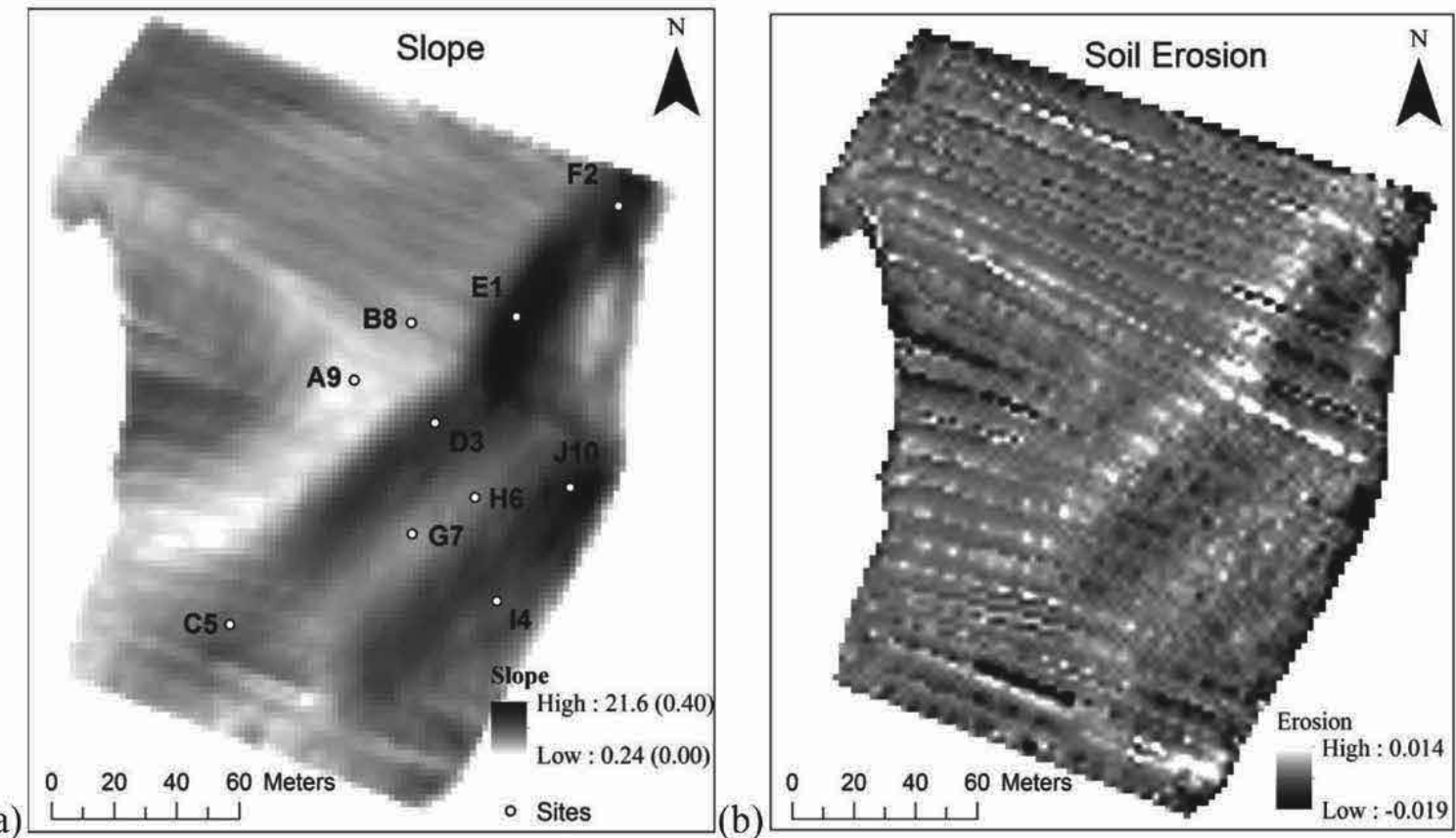

Figure 3 Maps of the research area showing (a) terrain and locations of the ten transects, with slope given in degrees and $\mathrm{m} / \mathrm{m}$ in parenthesis, and (b) soil erosion $(E)$ (m/year).

change in the way cows travelled across steeper slopes, restricting themselves to tracks roughly parallel to contour. On steep slopes, the magnitude of soil transport depended on whether or not a track intersected transects at which balls were placed. Ball transects at J10 and E1 (gradients 0.342 and 0.484 , respectively) ended up positioned between tracks by chance, resulting in little ball movement, although the soil above and below the transects had visibly moved to form the tracks. A track intersected the middle of transect F2 (gradient 0.394) and a corresponding greater rate of soil transport was observed (Figures $1 \& 2$ ). The formation of stock tracks was only observed at gradients steeper than 0.25 , and thus, the three transects identified were excluded when determining the relationship between gradient and soil transport (Figure 1).

Soil transport at transect B8 (gradient 0.061) was treated as an outlier and was also excluded when determining the relationship between gradient and soil transport, because a large amount of upslope movement was observed. As this transect was located at little gradient and close to a ring bale-feeder, the upslope movement may have been caused by some of the balls getting stuck in the hoof of a cow or a bike or tractor tyre and transported a large distance from its original position. It is possible that this also occurred at other transects, and may be the reason why four of the 200 steel balls were not found (missing balls were from transects I4, G7 and two from A9, and were all positioned at $50 \mathrm{~mm}$ depth).
It was evident from visual observations that pugging and soil damage occurred in the top 200 to $300 \mathrm{~mm}$ of the soil profile. However, significant downslope movement was measured in the top $100 \mathrm{~mm}$ of soil only (Figure 2).

Due to variability in the terrain, the soil flux $\left(q_{s}\right)$ estimated using equation 1 would have resulted in accumulation of soil (or net gain) in concave areas and erosion (or net loss) in convex areas (Figure 3b). Within the research area, gains of up to $19 \mathrm{~mm}$ and losses of up to $14 \mathrm{~mm}$ of soil during the period of this study were estimated, with data normally distributed around a mean of $0.1 \mathrm{~mm}$ erosion $(E)$.

\section{Discussion}

This study confirmed a linear relationship between soil transport and hillslope gradient for gradients up to 0.25 $\left(\right.$ c. $\left.13^{\circ}\right)$. Above this gradient, data became too highly scattered to determine if the same relationship existed on steeper slopes. Roering et al. (1999) demonstrated that soil transport by creep processes were best simulated with a non-linear model whereby transport rapidly increased as a critical slope gradient (c. 0.36 or $20^{\circ}$ ) was approached and exceeded; below the critical gradient, a linear slope dependent model was a reasonable approximation. Whether or not a non-linear model is appropriate for soil transport under forage crop grazing will need to be determined with more data from slopes of gradients above 0.25 .

The transport coefficient ( $K$ parameter) of the soil 
flux and hillslope gradient relationship quantifies the dependence of soil transport relative to gradient. The transport coefficient is positively related to power expended on the soil by disturbance processes and inversely related to soil strength (Roering et al. 1999). Under winter forage grazing, power expenditure is high due to dense stocking of large animals and the strength of the saturated soils is low. These factors, compounded by soil type and climate, are reflected in a $K$ value that is an order of magnitude higher than that of slopes under natural conditions reported by others. For example, Roering et al. (2002) found a mean soil transport coefficient $(K)$ of $0.012 \pm 0.008$ on gradients of 0 to 0.25 at a tectonically-active formerly forested hillslope in North Canterbury. Yoo et al. (2005) tabulate coefficients of $0.005 \mathrm{~m}^{2} /$ year and $0.0074 \mathrm{~m}^{2} /$ year for grass covered hillslopes in California, where soil transport was driven by gopher activity. McKean et al. (1993) report a coefficient of $0.036 \mathrm{~m}^{2} /$ year on gradients of 0 to 0.22 in California on a convex slope with grass vegetation and evidence of mechanical creep of highly plastic soils and biological mixing. When these values are considered in comparison to our coefficient of 0.11 $\pm 0.02 \mathrm{~m}^{2}$ /year, accelerated transport under winter forage cropping relative to natural systems is evident. This compares to a coefficient of $0.363 \mathrm{~m}^{2}$ per tillage operation for mouldboard ploughing across-slopes of 0 to 0.2 gradient and low convexity (Govers et al. 1996), suggesting cattle treading under a winter forage crop regime causes soil transport intermediate in intensity between natural processes and ploughing.

The rate of erosion resulting from soil transport varied with position in the landscape, with a net loss of soil on convex areas such as hillcrests and net gain of soil in concave areas (Figure 3b), a relationship also reported by Govers et al. (1996). Erosion calculated from hillslope curvature and $K$ (equation 2) produced predicted erosion rates of -19 to $14 \mathrm{~mm} /$ year, and our results showed that $56 \%$ of the total research area had a net soil loss, with a mean soil erosion rate of $0.1 \mathrm{~mm}$ /year. Of the eroding area, half was eroding at a rate greater than $1 \mathrm{~mm} /$ year. This greatly exceeds typical soil production rates of 0.03 to $0.08 \mathrm{~mm} /$ year (Montgomery 2007), and, therefore, will invariably lead to thinning of soil in convex areas. When it is considered that forage crop establishment and/or pasture re-establishment typically involve conventional cultivation, the total effect of this grazing system on soil erosion is likely to be greater than what is reported in this paper. Loss of soil via overland flow was not quantified and any losses due to this process are in addition to the erosion rates we have reported. Orchiston et al. (2013) reported average erosion rates of $0.01 \mathrm{~mm}$ via overland flow over a winter grazing period with similar soil, climate and grazing conditions to this study, and, therefore, similar losses can be expected from the study catchment area.

Direct loss of soil reduces nutrients available for plant growth, as they are adhered to the soil particles that are eroded, whilst soil thinning decreases rooting depth for plants and reduces the amount of water able to be held in the soil; all three effects have the potential to lead to a loss in crop or pasture production. In addition to these on-farm effects, soil dislodged beneath cow hooves is more easily transported and eroded by overland flow, ending up in waterways and causing eutrophication (Trimble \& Mendel 1995).

Areas of further research highlighted by this study include determining soil transport behaviour on slopes of gradient greater than 0.25 , and determining transport rates on different soil types. Transport due to cultivation also needs to be quantified under New Zealand conditions; this practice would almost always follow winter grazing and compound soil loss from convex areas. Cultivation methods that minimise downslope transport could then be identified. Methodological refinements could include: 1) modifying patterns of ball placement (e.g. an X pattern) to increase the chance of cows walking over balls where traffic becomes restricted to tracks on steeper slopes; 2) testing the relationship between ball displacement and soil movement using other tracers.

\section{ACKNOWLEDGEMENTS}

We thank Justin Pigou and Telford staff for the use of their cows and their management and data collection, and Tom Orchiston for his assistance with fieldwork and data collection. Dr Chris Pearson is thanked for his assistance in training to use the RTK GPS. The New Zealand Ministry of Business, Innovation and Employment partially funded this research through the Land Use Change and Intensification (LUCI) programme.

\section{REFERENCES}

de Ruiter, J.; Wilson, D.; Maley, S.; Fletcher, A.; Fraser, T.; Scott, W.; Berryman, S.; Dumbleton, A.; Nichol, W. 2009. Management practices for forage brassicas, Forage Brassica Development Group.

Govers, G.; Quine, T.A.; Desmet, P.J.J.; Walling, D.E. 1996. The relative contribution of soil tillage and overland flow erosion to soil redistribution on agricultural land. Earth Surface Processes and Landforms 21: 929-946.

Houlbrooke, D.J.; Paton, R.J.; Littlejohn, R.P.; Morton, J.D. 2011. Land-use intensification in New Zealand: effects on soil properties and pasture production. Journal of Agricultural Science 149: 337-349.

McDowell, R.W.; Houlbrooke, D.J. 2009. Management options to decrease phosphorus and sediment losses from irrigated cropland grazed by cattle and sheep. Soil Use and Management 25: 224-233. 
McKean, J.A.; Dietrich, W.E.; Finkel, R.C.; Southon, J.R.; Caffee, M.W. 1993. Quantification of soil production and downslope creep rates from cosmogenic Be-10 accumulations on a hillslope profile. Geology 21: 343-346.

Montgomery, D.R. 2007. Soil erosion and agricultural sustainability. Proceedings of the National Academy of Sciences of the United States of America 104: 13268-13272.

Morris, S.T. 2013. Sheep and beef cattle production systems. pp. 79-84. In: Ecosystems services in New Zealand. Ed. Dymond, J. Manaaki Whenua Press, Lincoln, New Zealand.

NIWA 2015. The National Climate Database. Accessed: 23/10/2015 http://www.cliflo.niwa.co.nz/

Orchiston, T.; Monaghan, R.; Laurenson, S. 2013. Reducing overland flow and sediment losses from winter forage crop paddocks grazed by dairy cows. In: Accurate and efficient use of nutrients on farms. Eds. Currie, L.D.; Christensen, C.L.Occasional Report No. 26. Fertilizer and Lime Research Centre, Massey University, Palmerston North, New Zealand.
Landcare Research, June 2015. S-map Online. Accessed: 14/10/2015 http://smap.landcareresearch. co.nz/smap

Roering, J.J.; Almond, P.; Tonkin, P.; McKean, J. 2002. Soil transport driven by biological processes over millennial time scales. Geology 30: 1115-1118.

Roering, J.J.; Kirchner, J.W.; Dietrich, W.E. 1999. Evidence for nonlinear, diffusive sediment transport on hillslopes and implications for landscape morphology. Water Resources Research 35: 853-870.

Trimble, S.W.; Mendel, A.C. 1995. The cow as a geomorphic agent -A critical review. Geomorphology 13: 233-253.

Yoo, K.; Amundson, R.; Heimsath, A.M.; Dietrich, W.E. 2005. Process-based model linking pocket gopher (Thomomys bottae) activity to sediment transport and soil thickness. Geology 33: 917-920.

Statistics New Zealand, 2014 (17 June). Livestock Numbers by Regional Council. Accessed: 14/10/2015 http://nzdotstat.stats.govt.nz/wbos/ Index.aspx?DataSetCode=TABLECODE7423 